\title{
INTERPRETAR OU DESCREVER NOTAS CRÍTICAS SOBRE O CONHECIMENTO ANTROPOLÓGICO ${ }^{1}$
}

JEAN BAZIN ${ }^{2}$

\author{
PABLO ANTUNHA BARBOSA (TRADUTOR) \\ CFCHS/UFSB, BRASIL \\ LUCIANA BEATRIZ ÁVILA (TRADUTORA) \\ CFCHS/UFSB, BRASIL
}

\begin{abstract}
RESUMO: Este texto que ora apresentamos é uma tradução inédita do capitulo Interpréter ou décrire. Notes critiques sur la connaissance anthropologique de Jean Bazin (1941-2001). O diretor de estudos da EHESS abriu novos caminhos para a antropologia ao questionar as operações subjacentes à prática da pesquisa de campo. Segundo ele, esse dispositivo não se limita a coletar fatos já existentes, mas produz um conhecimento próprio que se dá em situações singulares de interações compartilhadas. Bem descrito, ele não fornece apenas materiais empiricos a serem interpretados, mas também se deixa entender como um aprendizado recíproco e igualitário. A perspectiva pragmática desenvolvida por Bazin acompanha sua crítica radical ao holismo e ao culturalismo. Etnolinguista da prática da língua bambara (Mali) e analista das lógicas do campo politico, Bazin ampliou as perspectivas da antropologia, indo além de suas ideologias e utopias.
\end{abstract}

PALAVRAS-CHAVE: etnografia, abordagem pragmática, antropologia

ABSTRACT: This text is an unpublished translation of the chapter Interpréter ou décrire. Notes critiques sur la connaissance anthropologique by Jean Bazin (1941-2001). The director of studies at EHESS opened new paths for anthropology by questioning the operations underlying the practice of field research. According to him, this device is not limited to collecting already existing facts, but produces a knowledge of its own that takes place in unique situations of shared interactions. Well described, it not only provides empirical materials to be interpreted, but also lets itself be understood as reciprocal and egalitarian learning. The pragmatic perspective developed by Bazin accompanies his radical critique of holism and culturalism. An ethnolinguist in the practice of the Bambara language (Mali) and an analyst of the logics of the political field, Bazin has broadened the perspectives of anthropology, going beyond his ideologies and utopias.

KEYWORDS: ethnography, pragmatic perspective, anthropology

\footnotetext{
${ }^{1}$ Os tradutores Pablo Antunha Barbosa e Luciana Beatriz Ávila agradecem às Éditions de l'EHESS pela autorização para publicação desta tradução para o português, elaborada como parte das atividades do projeto CAPES-COFECUB, "Regimes nacionais da autoctonia. Situações autóctones e questão nacional nas Américas e Oceania", coordenado por João Pacheco de Oliveira e Alban Bensa (Edital nº 04/2017, Processo - 88881.143011/2017-01).

${ }^{2}$ Jean Bazin (1941-2001) foi um antropólogo francês diplomado em Filosofia na Ecole Normale Supérieure sob a orientação de Louis Althusser e doutorado em Antropologia com orientação de George Balandier na École des Hautes Études en Sciences Sociales (EHESS). Foi professor da Université de Paris V (René Descartes) e, posteriormente, membro e diretor do Laboratoire Genèse et Transformation des Mondes Sociaux (GTMS) da EHESS.
} 
Este texto não busca contribuir, ao menos diretamente, para a história de uma disciplina, a "antropologia" (ou a "etnologia"), e para os seus desenvolvimentos na Escola de Altos Estudos em Ciências Sociais (EHESS)". Uma "disciplina" é um modo de gestão institucional do saber. A vida "disciplinar" (defesa do território comum, rivalidade dos mestres, das escolas, dos métodos ou das doutrinas, etc.) tem, frequentemente, apenas uma relação de mediação com o saber em ação. Minha proposta é estabelecer, ou antes elucidar uma distinção entre as operações de conhecimento. Essa distinção não é específica à disciplina: o debate entre hermenêutica e pragmática atravessa o conjunto das ciências humanas. Ela separa modos de saber que, na prática, de uma forma ou de outra, todos nós conjugamos, a ponto de confundi-los. No entanto, que essa distinção apareça cada vez mais evidente - como esse texto busca mostrar -, abrindo mesmo a possibilidade de uma escolha lúcida entre os prazeres da interpretação dos costumes ou da exegese dos símbolos e a preocupação de uma explicitação das restrições "lógicas" ou "sintáticas" da ação em uma dada conjuntura histórica, indica uma transformação das condições do nosso saber, cujos efeitos já se fizeram e se farão amplamente sentir na EHESS.

Imaginem uma experiência que, embora eu testemunhe direta e atentamente os seus atos, tenho que admitir que, mesmo tendo considerado tudo, eu não sei o que eles fazem - "eu" sendo um observador indeterminado, animado por uma curiosidade erudita pela variedade dos comportamentos humanos, e "eles" uns observados quaisquer. A condição de tal experiência é um certo deslocamento. Na medida em que um mundo me é familiar, eu sei do que se trata e não tenho por que investigar ${ }^{4}$. Se estou "em casa", não tenho nada a conhecer, pois eu me reconheço.

Observar o que estes humanos fazem, i.e., constituir em objeto de conhecimento seus comportamentos atuais, supõe uma distância, mesmo que mínima, em virtude da qual aquilo que eles fazem não me é ou deixa de me ser familiar. Trata-se do ponto de partida do processo de investigação. Talvez fosse melhor dizer que observá-los é precisamente essa distância. A distância que minha capacidade de os observar manifesta - eu não sou daquele mundo - não é, portanto, uma espécie de desvantagem original que pesa sobre esse conhecimento, mas sua condição. Exceto para quem confunde conhecimento (eu sei o que eles fazem) e identificação (eu sou um deles). Se eu fosse ou me tornasse um deles, aprender o que eles fazem seria vão, e, mesmo que, por hora, ignore isso, não implica que eles já o saibam, isto é, que eles tenham um conhecimento erudito de suas práticas análogo ao que pretendo adquirir.

\footnotetext{
${ }^{3}$ Esse texto foi publicado originalmente em J. Revel \& N. Wachtel (1996) e reeditado em J. Bazin (2008).

${ }^{4}$ Sobre "compreender" e "interpretar, ver L. Wittgenstein, 1980 [1969], p. 55-56: "Naturalmente, pode acontecer que eu interprete signos, que dê uma interpretação a alguns signos: mas não é sempre que compreendo um signo".
} 
A "distância" é o conjunto das condições e das operações que contribuem para que um mundo qualquer venha a ser familiar para mim.

Não se trata de uma qualidade que algumas sociedades estejam mais bem equipadas que outras, conferindo, dessa forma, um "privilégio" epistemológico àqueles que as observam". Na verdade, uma "sociedade" não é uma coisa que posso observar. Não importa quão distante ou pequena seja, o ponto de vista de Sirius não me é mais acessível. Nunca observo outra coisa que não sejam situações. Observar uma situação (diferente de observar um planeta) é não se perder. Se eu a observo, eu o faço, no entanto, como um estrangeiro. Por interesse acadêmico, certifico-me de que me encontro (mesmo que isso signifique provocá-las) em situações que apresentem um grau relativo de estranhamento, mas o suficiente para que, não sabendo o que eles fazem, me comprometa a aprender. Na medida em que o mundo deles não é o meu, ele é para mim um objeto de conhecimento. Mas se trata de um objeto que me é dado em uma situação que eu e eles compartilhamos ${ }^{6}$. Essa tensão entre copresença e distância define aquilo que chamamos (em oposição ao laboratório ou ao gabinete de trabalho) "o campo".

Se não sei o que eles fazem, também não sei realmente do que sou ignorante, isto é, qual é a natureza daquilo que devo aprender para deixar de sê-lo. No entanto, não posso observar o que quer que seja sem levantar, geralmente contra a minha vontade, uma hipótese sobre o que há para ser observado.

Ou então - hipótese (1) - minha ignorância é de ordem semântica. Se o comportamento deles me parece estranho, é porque ele é "expressivo", e o que ele expressa, seu "sentido", está oculto para mim. Devo, portanto, descobri-lo, inventá-lo, adivinhá-lo ou fazer com que alguém o explique para mim.

Em 5 de outubro de 1931 , em Sanga, eu observo "vários homens" que, "em torno de um local rochoso", "decoram pequenas hortas na areia, conjuntos de quadrados decorados com formas variadas, com pequenos pedaços de pau, com pedras, etc. Em volta dessas pequenas hortas, jogam-se amendoins". "Eu" é, nesse caso, Michel Leiris, em companhia de Marcel Griaule. Se se verificasse, ao observar com mais proximidade,

\footnotetext{
${ }^{5}$ A observação das sociedades "que por falta de um termo melhor denominamos de primitivas" é, diz LéviStrauss, "privilegiada, porque distante" (1973 [1962], p. 37-39). Ao mesmo tempo por suas propriedades inerentes (elas transmitem uma imagem "em redução" e "em equilíbrio" da vida social) e também porque elas "oferecem, comparadas à do observador, os desvios mais consideráveis", essas sociedades "constituem casos privilegiados" que "permitem perceber o modelo por trás da realidade", assim como o "afastamento dos corpos celestes" fez com que a astronomia fosse "o terreno onde as ciências exatas deveriam dar os seus primeiros passos" (ibid., p. 80). [Para a tradução dessas citações, foi utilizada a quarta edição da tradução brasileira de Antropologia Estrutural II, publicada pela editora Tempo Brasileiro em 1993, p. 3335 e p. 72 , ndt].

${ }^{6}$ Sobre esse aspecto, ver as análises de Gérard Althabe. O conhecimento é o produto de uma "comunicação compartilhada" com sujeitos encontrados, não em um "evento quase experimental" construído pelas necessidades da pesquisa. É nesta situação conjuntural e singular, em que sou um dos autores, que afasto esses sujeitos, constituindo-os em "atores de um universo social" que me é estranho (G. Althabe, 1990). ${ }^{7}$ M. Leiris, 1981 [1934], p. 105.
} 
que eles estão armando uma armadilha, eu constataria que eles não o fazem da mesma forma que os camponeses da região das Ardenas: sendo a ação deles puramente "técnica" (ou podendo ser, com razão ou não, considerada dessa forma), ela não me pareceria enigmática, apenas diferente. Armar uma armadilha, quaisquer que sejam os métodos usados (que eventualmente eu tentarei descrever minuciosamente), é uma atividade que não tenho por que procurar o "sentido". Mas não é esse o caso: não faço a menor ideia do que eles "querem dizer", quando decoram as rochas de forma tão bizarra. Porque não conheço, faz com que o comportamento deles se torne "expressivo"8. Sua própria estranheza indica que reside ali "um sentido", mas não sei qual é. O "informante" de Leiris - Ambara, um nativo que sabe um pouco de francês - Ihe explica então que, "à noite, chegam os yourougou (espécie de chacal), que esparramam tudo. De manhã cedo, os homens voltam e, a partir da devastação deixada por esses animais, fazem presságios"." O comportamento deles significa, portanto, uma crença, nesse caso uma crença dogon, mas essa crença em si, o que significa?

Ou então - hipótese (2) - minha ignorância é de ordem pragmática. Eu os vejo agir, ou discorrer, logicamente à sua moda que não é a minha, mas, sobretudo, não sei de que assunto estão tratando, da mesma forma quando, às vezes, testemunhamos uma conversa ou uma briga sem compreender $0 \times$ da questão.

Presencio, como Marc Augé o fez em um dia de fevereiro de 1967, alguns funerais em Grand-Jacques ${ }^{10}$. Começa-se a interrogar o cadáver: ele responde "sim" ou "não", "fazendo" avançar ou recuar aqueles que o carregam, o que, em si, é tão estranho quanto interrogar um "chacal", a partir da leitura dos rastros de seus deslocamentos noturnos. No entanto, o problema não é saber porque, entre os aladianos, os mortos falam, ou qual é o "sentido" dessa instituição, mas porque esse morto, Y, diz o que diz, porque ele acusa $X$ de tê-lo matado "duas vezes"; e essa própria acusação não me é o suficiente para pensá-la como um comportamento exemplar da crença que os aladianos têm sobre a bruxaria representação que alguns informantes locais vão eventualmente me prestar (as sociedades de bruxos, refeições canibais etc.) -, me é necessário que aprenda porque ela é, nessa determinada circunstância, na determinada situação que a observo, um diagnóstico plausível: porque, se isso não fosse assim, o interrogador e os carregadores do morto não a teriam formulado publicamente.

\footnotetext{
${ }^{8}$ Sobre a diferença entre "ações técnicas" (que modificam o estado físico do mundo) e "ações expressivas", ver E. Leach, 1976, p. 9. No entanto, toda "ação técnica" é suscetível de ser considerada como "expressiva" ("A forma como preparo o café e os instrumentos que utilizo no processo dão informações sobre a minha formação cultural").

${ }^{9}$ Ibid. Sou eu (J. B.) que distingue a observação bruta do comentário, já que o texto de Leiris apresenta-se como a narração de um acontecimento único. Leiris especifica que eles estão acompanhados por Ambara e por um de seus irmãos mais velhos. Ambara Dolo é seu "informante" faz alguns dias ("Em uma língua não muito clara, mas que absorvo literalmente, Ambara revela-me um bocado de coisas", ibid., p. 98).

${ }^{10}$ M. Augé, durante sua estadia na região Aladiana (1965-1967), acompanhou o desenrolar de vários "assuntos", mais particularmente assuntos de herança, em que se recorre ao interrogatório do cadáver (M. Augé, 1969, p. 204 e seguintes. Sobre a forma de fazer o interrogatório, ver p. 214-215).
} 
Essas são duas formas de reagir à situação de estranhamento, duas maneiras de definir implicitamente minha ignorância e, portanto, de transformá-la em conhecimento. É muito difícil, no "campo", não as combinar. Meus pedidos de explicação são ambíguos e produzem respostas dos dois tipos, meus interlocutores (ou "informantes") podem, de acordo com o caso, ou "traduzir" para mim o sentido do que fazem, ou me indicar as razões conjunturais de suas ações. Dessas duas atitudes de pesquisa, podemos apenas dizer que a primeira, que não é menos erudita que a segunda, é mais "natural" ou espontânea". Em virtude de uma ilusão de perspectiva cujo poder é difícil combater, a distância em que me encontro para observar me transforma, de fato, facilmente em espectador. É espectador quem quer que seja que suponha que "os outros" estão atuando: eles não fazem simplesmente (ou não verdadeiramente) o que fazem, eles também me deixam ver e ouvir. 0 que parece ser uma ação (lavar as mãos compulsivamente) é, na verdade, um ato de comunicação (representar, no sentido de "to perform", Macbeth) ${ }^{12}$.

$\mathrm{Na}$ medida em que me "dizem" alguma coisa, o que é verdadeiro para o ator em cena, mas não necessariamente para aqueles homens sobre as rochas ocupados em fazer adivinhações, é necessário que eu escute. Se há mensagem, ela tem um sentido, caso contrário, ela ainda não é uma mensagem ou deixou de sê-la. Tudo se passa como se eu estivesse, diante do que eles fazem (como eles diante das pegadas do "chacal"), em posição de hermeneuta: "Algum sentido é ao mesmo tempo dado e retirado, porque ainda resta alcançá-lo, mesmo correndo o risco de uma interpretação"'s.

O que Leiris anota no seu diário, ao término desse passeio sobre os rochedos de Sanga, é um costume, neste caso, um costume dogon. Um costume é um comportamento mais "seu sentido". O primeiro é observado, faz parte da ordem dos fatos, o segundo é sugerido por um comentário, é uma interpretação. Se Leiris, na falta de algo melhor, tivesse anotado apenas a observação tal como no seu diário, ela ainda não seria um costume. Da mesma forma, Ambara poderia ter se

\footnotetext{
11 É por isso que, às vezes, a segunda é chamada de "crítica". Veja-se o que Alban Bensa chama de "antropologia crítica", $i$. e., uma forma crítica de praticar a antropologia e não uma denúncia da própria prática antropológica.

${ }^{12}$ A ideia de que aquilo que observamos, nesta situação de ignorância, são signos, não é, evidentemente, apenas da "escola francesa" de etnologia que tomo aqui como exemplo. Ela atravessa toda a história da disciplina. Sem dúvida, é em Lévi-Strauss e Leach que encontramos as formulações mais explícitas - "para a antropologia, que é uma conversa do homem com o homem, tudo é símbolo e signo que se coloca como intermediário entre dois sujeitos" (Lévi-Strauss, 1973 [1962], p. 20); "itens individuais do comportamento observado e detalhes individuais dos costumes podem ser tratados como análogos às palavras e frases de uma língua, ou trechos de uma performance musical... Minha preocupação atual é discutir como os antropólogos, como observadores, devem definir a questão de decidir quais costumes, além dos costumes verbais, podem ser considerados como possíveis de 'significar"' (Leach, 1976, p. 6).

${ }^{13}$ V. Descombes, 1983, p. 17.
} 
contentado em dar uma resposta em tom enigmático: "ah, é desse jeito! " e, nesse caso, Leiris teria anotado que "é um costume", mas não qual costume é. Eu também poderia, como um observador apressado ou negligente, postular um sentido ("trata-se, sem dúvida, de um rito para proteger as plantações de amendoim"), produzindo, assim, um pseudocostume, mescla de verdade (o comportamento foi, de fato, observado) e de falsidade (o sentido não é o correto). Um etnógrafo sério se baseia em um comentário indígena, o que lhe dá um sentido autorizado e, então, um costume autêntico, mas todos os comentários não dão o mesmo sentido e suas interpretações não são nunca totalmente diferentes das minhas. O desprezo é sempre possível ${ }^{15}$. A tarefa hermenêutica é sempre indefinida.

Diante de qualquer estado de perplexidade, em que se comprove que eu não sei o que eles fazem, pode ser encerrada por uma proposição do tipo é o costume deles. O que seja costume deles (ou seja, não os meus), ao mesmo tempo justifica a minha ignorância e a transforma em saber. Um saber do gênero etnológico.

Suponho, explicitamente ou não, que a humanidade é uma espécie de super-sociedade composta de sujeitos coletivos: portanto, eu "encontro", então, em "campo", os sinais e os traços nos quais se reconhecem a singularidade de um povo (ethnos, volk) ${ }^{16}$ e que, aos poucos, se revelam o modo de vida e a visão de mundo que lhes são próprios. Um comportamento torna-se um costume, na medida em que é visto como o índice ou a manifestação de uma crença ou de uma representação que presumimos ser coletivamente partilhadas. Cada um desses costumes permite que se descubra a natureza de fragmento de uma totalidade ainda inédita. Por isso, o apetite e a impaciência do etnógrafo ("fico desesperado de jamais conseguir penetrar a fundo em qualquer coisa que seja. Segurar apenas pedaços de um monte de coisas me deixa louco de raiva", comenta Leiris ${ }^{17}$ ). De fato, como sabemos, o rastro desse "chacal" (que é uma raposa) levará longe ${ }^{18}$. O acontecimento registrado nesse dia é apenas o primeiro "traço" de uma partitura desconhecida, alguns dirão secreta, que os Dogons "interpretam" diante de mim, para não dizer para mim. Para ser honesto, um texto raro, eternamente ausente, mas que, por definição, suponho já estar aí, em algum lugar, senão fora do tempo, ao menos fora deste tempo, único e

\footnotetext{
${ }^{14}$ Leiris fica irritado com "todos aqueles a quem perguntamos a razão de tal adereço simbólico ou de tal rito de sentido distante e que respondem tranquilamente: “ah, é desse jeito!” (1981 [1934], p. 95).

${ }^{15}$ Como destacado por Vincent Descombes (1983), a hermenêutica não é uma arte da decodificação. Não se trata de descobrir, de uma vez por todas, qual é o número que se codificou a mensagem.

${ }^{16} \mathrm{Ou}$, por extensão, de uma comunidade qualquer, por mais limitada que seja. Posso ser o etnógrafo de um vilarejo, de um grupo de fãs de "hip-hop", da rua ao lado... Qualquer que seja o conjunto escolhido, na medida em que a pesquisa lhe confere alteridade (em relação a mim) e autonomia (em relação ao resto do mundo social), sempre haverá um meio de "revelar" uma "subcultura" específica, desapercebida até então. 171981 [1934], p. 105.

${ }^{18}$ Até essa surpreendente soma teológica que é Le renard pâle, de M. Griaule e G. Dieterlen, 1965.
} 
inteiramente escrito antes que comece a lê-lo - ainda que, na prática, lêlo seja ao mesmo tempo escrevê-lo ${ }^{19}$.

Quando interpreto o significado do que eles fazem, não descrevo o que eles fazem. O costume é um conteúdo de sentido extraído de uma situação. Eu não o invento, eu o "colho" ou o destaco, deixando-o de lado, um esquecimento "produtivo" (no sentido que se pode dar a um malentendido) da atualidade - o aqui-agora do que esses homens, fulano e sicrano (e não "os Dogons"), estão fazendo, a urgência de seus "negócios", de suas paixões ou de seus interesses. Nós não saberemos nunca quem eram essas pessoas sobre as rochas, em Sanga, no dia 5 de outubro de 1931, nem que "verdade" eles buscavam descobrir ou se certificar, ao fazer aquela operação de adivinhação.

Em vez de poder dizer o que eles fazem, o que suporia que eu tivesse tentado aprendê-lo, eu faço do que eles fazem o exemplo de uma maneira dogon de se comportar. A própria estranheza de sua conduta a meus olhos, o fato de que ela não tem sentido para mim, mas que, não suponho que seja insensata, me conduz a buscar um sentido dogon, aquele que Ambara vai fornecer. O que esses homens fazem, na medida em que, espectador, eu os institua, sem o seu conhecimento, atores de sua "cultura", é, portanto, comportar-se como Dogon. No entanto, não é esse o caso realmente: ser Dogon, ou parecer ser, não é, provavelmente, nesta circunstância, a principal preocupação, nem o que está em jogo em suas práticas, mesmo que seja possível que em outras circunstâncias seja esse o caso. Hoje, saindo de Sanga, no início do itinerário estabelecido que os guias oficiais o fazem percorrer, o turista, como eu mesmo experimentei recentemente, pode ver sobre uma grande placa de rocha 0 dispositivo adivinhatório esperando seu hipotético yourougou e o comentário apropriado lhe é imediatamente fornecido, mesmo sem tê-lo pedido: uma parte dos moradores de Sanga e dos vilarejos vizinhos está agora preocupada, pelo menos em tempo parcial, em ser Dogons.

Em vez de tratar implicitamente a situação como uma cena exemplar em que se deixa ler um texto latente (sua cultura, a "alma do povo"...), posso - hipótese (2) - tratá-la diretamente como o meu objeto, levar a sério o seu presente imediato. Dessa forma, não registro mais comportamentos "expressivos", isto é, comportamentos portadores de um sentido, mas ações, ou elementos de uma ação complexa que implica múltiplos parceiros. Uma ação pode ser sensata (razoável, bem-sucedida, prudente, eficaz...) ou insensata, mas apenas segundo um ou outro sentido da palavra "sentido".

O que observo, são, na realidade, "jogadas”, hábeis ou desajeitadas, ganhadoras ou perdedoras, de um "jogo" no qual caí sem querer. No entanto, sem conhecer as "regras do jogo", eu não o "conheço". Por não estar familiarizado nem com as posições ocupadas, nem com os

\footnotetext{
19 A questão não é de "desconstruir" o texto etnográfico, mas de tomar consciência do pressuposto semiológico sob o qual o etnólogo considera implicitamente o que ele observa como um quase-texto ao qual tem que fornecer o comentário interpretativo.
} 
interesses em jogo, nem com as formas de defendê-las ou de impô-las, muitas vezes me é muito difícil perceber que os comportamentos que observo são ações. Posso, como Alban Bensa, gravar mitos estranhos sobre a origem do mundo horas a fio, aparentemente narradas para mim, para satisfazer a minha curiosidade amadora sobre as "coisas kanaks", mas também para o prazer dos ouvintes, sem perceber o que está em jogo em cada uma das operações que o orador se utiliza da minha presença e da autoridade que meu estatuto de estrangeiro e meu gravador conferem à palavra, para reivindicar e tentar legitimar uma pretensão à autoctonia ou à chefatura ${ }^{20}$.

Minha ignorância, neste caso, não é uma incapacidade de interpretar, mas uma incapacidade de descrever o que eles fazem. "B move seu cavalo em F3" é uma descrição exata do que faz B, mas que supõe um conhecimento mínimo de xadrez. Se eu não o tenho, qualquer que seja a forma que, de uma maneira ou outra, tente entender esse movimento, não posso dizer que saiba o que $B$ faz. E quanto menos sei descrever, mais sou tentado a interpretar. Quanto menos percebo, por falta de ter ou procurar a informação necessária, que, na realidade, eles estão disputando o poder, resolvendo um conflito de terra ou negociando uma aliança matrimonial, todos assuntos que em outras situações poderiam me parecer perfeitamente familiares, mais me impressiona a estranheza irredutível de seus mitos, ritos ou crenças. Inversamente, quanto mais aprendo a descrever o que eles fazem, mais se dissolve a sua insondável alteridade, esse abismo que parecia me separar para sempre da forma como eles veem o mundo (da sua "mentalidade").

Essa situação de observação, que mostra que eu não sei o que eles fazem, abre, portanto, a escolha de duas vias. Suponho - hipótese etnológica - que existe um "ponto de vista nativo" que, através de uma mistagogia prévia sob a liderança de alguns iniciados importantes, devo acessar para deter, finalmente, o sentido do que eles fazem. Ou suponho - hipótese antropológica - que o comportamento desses humanos não é outro, i.e., outro que não o meu, mas apenas diferente ${ }^{21}$. Nesse caso, não se trata de ser iniciado a esse conhecimento íntimo que o "outro" supostamente deveria ter sobre si mesmo - projeção ilusória da minha própria ignorância -, mas de aprender a descrever como eles agem. No final do processo, que eu saiba dizer, ao menos parcialmente, o que eles fazem, é a prova de que, por mais diferente que seja seu comportamento, é pensável que ele seja o meu: com um pouco de empenho e com bastante falta de jeito, à maneira de um jogador iniciante desprovido de conhecimento, poderia arriscar-me nos seus assuntos, contar com astúcia mitos de origem ou propor um diagnóstico adequado, no caso de morte

\footnotetext{
${ }^{20}$ Ver, entre outros, A. Bensa e J.-C. Rivierre, 1988. Quando não se trata mais de um texto morto, retirado das condições práticas de sua enunciação, o mito pode ser ouvido como um discurso político: ele põe em prática uma retórica da transposição dos interesses particulares e dos apoiadores a partir de fórmulas de aspecto elevado e geral (ver J. Bazin e A. Bensa, 1979, p. 23).

21 O termo "outro", como nota Vincent Descombes (1989, p. 89), presta-se a muitas confusões, porque "ignoramos a diferença entre o outro no sentido de alterum, o outro dos dois termos de um casal, e o outro no sentido de aliud, alguma outra coisa em um sentido indeterminado".
} 
por bruxaria ${ }^{22}$. O conhecimento antropológico tem o efeito de reduzir a alteridade, não de promovê-la.

Basta que eu adote a posição do hermeneuta para metamorfosear um vilarejo da Normandia ou uma empresa de Paris em lugares com uma aparência de alteridade essencial. Inversamente, posicionar-me a uma distância tal que me permita descrever o que eles fazem para o saber não implica, necessariamente, aventuras exóticas. Se imaginamos que é mais fácil na Nova Guiné do que em Seine-Saint-Denis, é porque confundimos a descoberta, ou mesmo a celebração do "outro", com a experiência antropológica, que o contato (sem falar do primeiro contato) com as populações desconhecidas nunca é uma condição extrema ${ }^{23}$. Nenhuma sociedade fornece ao antropólogo uma "experiência já pronta" ${ }^{24}$ e as condições dessa experiência podem acontecer em qualquer lugar. Basta um pequeno e casual deslocamento - mudança de lugar ou de olhar para que, através de uma variação do famoso "V-Effekt" de Brecht, uma atividade que, no cotidiano, me é familiar - fazer compras, assistir a um jogo de futebol, viajar de avião, etc. - se torna para mim, senão uma atividade enigmática, ao menos uma atividade suficientemente estranha para poder se transformar em um objeto de descrição. É verdade que, nesse caso, sei fazer o que eles fazem - que eu esteja na feira de Carpentras ou da praça Aligre, sei como devo me comportar - mas isso não significa, no entanto, que eu saiba o que faço, da mesma forma que saber contar não significa que eu saiba aritmética ${ }^{25}$.

A distinção de duas etnologias, uma do "próximo" e a outra do "longínquo" - com sua dialética do desvio e do retorno - certamente pertence à história da disciplina, mas ela é epistemologicamente sem fundamentação. Se é verdade que o que me guia é um certo interesse "antropológico" (pois o prazer angustiado pelo exótico não é um detalhe), então, o gênero humano começa com meu vizinho. Basta justamente que, graças a um exercício mental não isento de certa perversidade, deixando de forma fictícia de viver no mesmo mundo que ele e instituindo-o como ator de outro mundo, eu o observe. Como o "filósofo" que, segundo

\footnotetext{
22 "Bonifácio [...] voltava ao caráter indiscutível da experiência: nem seus doentes, nem suas curas haviam sido ilusões: ele tinha 'sentido' o cadáver pesar sobre seus ombros e o forçado a andar ou a recuar [...]. No que se referia a mim, eu era sensível à lógica do sistema: acho ter sido capaz de ter tido um olhar verossímil sobre o diagnóstico de uma ou outra morte; a falta de modéstia da aproximação é muito evidente para que peçamos desculpas: acho que sinto profundamente a verdade das palavras de Evans-Pritchard quando, em essência, ele se diz capaz de raciocinar na lógica daqueles que ele estuda” (M. Augé, 1975, p. 313).

${ }^{23}$ De acordo com Jean-Claude Passeron (1993), quando a antropologia deixa de lado ou perde seus "objetos longínquos e enigmáticos" para se repatriar nas periferias das grandes cidades francesas, ela torna-se indistinguível da sociologia. Mantenho, contudo, que descrever o que é "ir à feira" não é fazer a sociologia de uma feira, são operações distintas que podem, além disso, ser empreendidas tanto por "sociólogos" como por "antropólogos". Percebe-se que Passeron junta-se aqui a Lévi-Strauss: quando aplicamos às "sociedades contemporâneas", em oposição às sociedades "ditas primitivas", nós praticamos a etnologia "em estado diluído" e não mais em "estado puro": seu objetivo se "confunde com outros objetos" (C. LéviStrauss, 1973 [1962], p. 37).

${ }^{24}$ Ver C. Lévi-Strauss, ibid., p. 24. Daí esse diagnóstico pessimista: "Está chegando o dia em que a última das culturas que nós chamamos primitivas terá desaparecido da superfície da terra, e que perceberemos, mas tarde demais, que o conhecimento do homem está privado para sempre de suas bases experimentais" (ibid., p. 65).

${ }^{25}$ Ver Michèle de La Pradelle, 1996.
} 
Nietzsche, deve ser capaz de "sentir como estranho aquilo que lhe é mais próximo": para Heródoto, ancestral de geógrafos e etnólogos, é necessário alguns Citas e outros Masságetas, mas, para Heráclito, os Gregos são suficientes ${ }^{26}$.

Na praça de Grand-Jacques, Y, a "vítima", acusa $X$ de assassinato por bruxaria ("duas vezes"). O morto é movimentado até que "ele indique" a casinha de uma velha de sua linhagem materna. Relatar o acontecimento é uma coisa (registrar em um diário, por exemplo, o que aconteceu, a identidade das pessoas, seus propósitos etc.), descrever a ação que testemunhei é outra. Para isso, devo aprender que o poder de agressão de uma bruxa normalmente "ataca" dentro da linhagem matrilinear, que uma velha, por sua "debilidade", é uma acusada ideal ${ }^{27}$ etc. Passo a passo, é necessário que, aos poucos, eu conheça a série de táticas possíveis (suspeitar não é acusar), o sistema das posições susceptíveis de serem ocupadas pelos agentes, e também os critérios de avaliação da "força" e da "fraqueza" relativas que indicam aqueles que as ocupam².

Se a acusação for "bem-sucedida", é porque ela é plausível. Não se acusa de bruxaria qualquer pessoa por qualquer motivo. Quem faz isso pode ser tomado por um insensato ou por ridículo. É um comportamento que, aos poucos, percebo que respeita certas regras. A mesma coisa acontece durante esses "processos" generalizados e permanentes entre condôminos de um mesmo HLM na ZUP'29 "Bellevue" de Nantes, um interminável encadeamento de alegações e acusações que constitui a trama dos acontecimentos cotidianos que eu observo - "eu", neste caso, é Gérard Althabe - como representações que os agentes me fornecem das relações que eles mantêm entre $\mathrm{si}^{30}$. Se as acusações fossem possíveis e pensáveis de qualquer posição e em qualquer direção, estaríamos em um mundo "a-simbólico" (ou seja, indiferenciado ou caótico). Um mundo como esse não poderia ser descrito. Mas um mundo não é "simbólico" ao "significar" ou "expressar" alguma outra coisa. Pensemos talvez, como propunha Lacan ${ }^{31}$, em uma biblioteca e no que quer dizer que um livro está ou não está em "seu" devido lugar. Algumas regras (por exemplo, um código de barras) definem itens, posições e relações.

\footnotetext{
26 "Fragments posthumes. Hiver 1872-1873", 1990.

${ }^{27} \mathrm{Na}$ realidade, trata-se do chefe da linhagem, primo do acusado, que está na mira, mas ele só pode ser um suspeito, acusá-lo de forma direta seria, então, ousado. Cúmplice presumido da "bruxa" de quem ele herdou, ele também será acusado algum tempo depois. Sobre esse assunto, muito simplificado aqui, ver M. Augé, 1969 , p. 210.

${ }^{28}$ Ver M. Augé, 1975.

${ }^{29}$ Uma HLM, sigla para "Habitation à Loyer Modéré”, é um imóvel de baixo custo ou aluguel relativamente barato, reservado a cidadãos de baixa renda, normalmente subvencionada pelo Estado e com regulamentação própria, localizada em uma ZUP, área a ser urbanizada em prioridade (ou "zone à urbaniser en priorité"). As ZUPs são parte de uma política de planejamento urbano na França, ocorrida entre 1959 e 1967, com o objetivo de atender à crescente demanda por moradia [ndt].

${ }^{30}$ Ver "Procès réciproques en HLM", em G. Althabe, C. Marcadet, M. de La Pradelle e M. Sélim, 1985.

31 J. Lacan, 1994, p. 38.
} 
Não que aqueles que observo, em Grand-Jacques ou em Nantes, estejam aplicando regras. Na medida em que um jogo me é familiar, eu o entendo e o pratico sem ter necessidade de me referir às regras. A mesma coisa acontece ao falar a minha língua, não é aplicar a gramática da língua francesa ${ }^{32}$, mesmo que possa acontecer, a respeito de alguma questão delicada, que consulte o "Grevisse" 33 , da mesma forma como os aladianos consultam um "vidente", quando as respostas do morto não são muito transparentes. No entanto, descrever esse jogo é formular as regras, isto é, enunciar o escopo das "jogadas" possíveis e plausíveis.

Poderíamos dizer que o que me falta para poder descrever as suas ações é justamente sua cultura. Mas este não é o caso. Sou eu quem formulo as regras às quais suas ações devem se conformar, e não eles. É a minha forma de conhecimento, i.e., de poder dizer o que eles fazem. Não preciso supor que eles "a" tenham em algum lugar, em suas mãos, como um programa dentro de uma máquina. Essas regras não são nem a causa e nem a razão de suas ações, mas a maneira que tenho para descrevê-las. Descrever as regras do jogo não é explicar o motivo dessa jogada. Apenas a história da linhagem e dos conflitos internos anteriores, como também, retrospectivamente, a história de seus episódios futuros, é que permitem explicar o acontecimento. O fato é que essa ação, quaisquer que sejam suas causas e suas razões, permanece no campo do possível e do plausível.

Pelo fato de que uma acusação de bruxaria como essa possa ser formulada sem despertar espanto, posso induzir, por exemplo, que é natural entre os aladianos que um indivíduo possa agredir de duas formas, "de verdade" e "em dobro". De fato, poderei estabelecer, graças a uma pesquisa apropriada, que os aladianos têm - isto é, são capazes de formular - uma teoria da pessoa humana (combinação instável de instâncias diferentes em que uma pode ser portadora e a outra vítima do poder de agressão de bruxaria...) que "corresponde" às práticas observadas. Para alcançar isso, reúno alguns informantes, selecionados precisamente por sua "cultura" (eles conhecem mais que outros sobre a matéria) e, na serenidade de uma conversa noturna na varanda, em resposta às minhas questões, eles se esforçam por satisfazer a qualquer custo minha curiosidade, eles "me explicitam" essa teoria, i.e., eles contribuem comigo para escrevê-la. "Ter uma teoria da pessoa" é entregar-se a uma atividade social singular de ordem "teórica", "escolástica", como diria Bourdieu - atividade que, por mais instigante que seja, não tem nada a ver com: acusar alguém publicamente de bruxaria.

Posso muito bem dizer: como eles se acusam mutuamente de bruxaria, é porque eles "creem" na existência "em dobro". Coloco, portanto, em relação um costume e uma representação (hipótese etnológica). Mas não posso dizer: que, ao movimentar o morto $\mathrm{Y}$, eles

\footnotetext{
${ }^{32}$ Uso aqui a distinção feita por Wittgenstein entre uma ação conforme uma regra e uma ação que implica a regra, $i$. e. que faz referência a uma expressão da regra. A maioria dos comportamentos humanos (começando pela linguagem) está de acordo com regras sem implicar a regra.

${ }^{33}$ Grevisse é uma gramática francesa, obra de referência escrita por Maurice Grevisse, gramático belga [ndt].
} 
acusam $X$ de bruxaria, eles implementam uma representação aladiana do mundo (da pessoa, da doença, da morte etc.). Eles não testam uma hipótese: na medida em que a "jogada" foi bem jogada, a culpa de X é uma evidência para eles. Não se trata de uma conclusão tirada graças a certos indícios: como é uma evidência, tudo faz sentido. Como isso não acontece comigo, alguns deles aceitam, eventualmente, me fornecer uma "explicação". No entanto, as observações que anoto nesta ocasião, e que me permitem formular eventualmente uma "teoria" (ou uma "ideologia") aladiana, são os comentários sobre o acontecimento, e não suas causas.

\section{6}

O que define a situação observada é a sua atualidade: o espaçotempo presente que efetivamente reúne todas as reais condições de sua ação. Ela não é, em si, aladiana ou dogon. A partir do momento que faço parte dela, é o suficiente para atestá-la. É verdade que eu não sou um protagonista do mundo deles; ao não cobiçar, em Grand-Jacques, nenhuma posição de autoridade no seio das linhagens, não corro o perigo de fazer parte dos "suspeitos", mas eu sou, volens nolens, um dos atores da situação: eles me atribuem um papel. Malinowski não observa Omarakana da sua barraca, mas sim Omarakana com uma barraca bem em seu centro - o que aparece apenas no seu diário e do seu ponto de vista: os niggers são também vizinhos que incomodam e ele só consegue relaxar refugiando-se entre os europeus da vizinhança ${ }^{34}$ ou na leitura de "romances de segunda categoria" 35 . Mas o que sabemos da forma como os Trobiandeses tratam, ou eventualmente usam, a presença, não menos enfadonha, desse eterno perguntador que nunca está satisfeito das respostas que lhe são dadas?

Em Grand-Jacques em 1967, do conjunto de tudo aquilo que determina aqueles que agem a agir como eles o fazem, existem algumas "regras do jogo" e algumas dificuldades que não posso dizer que sejam externas, mesmo que eles não sejam propriamente aladianos. Por exemplo, ter uma linda plantação de café ou um primo funcionário público em Abidjan são ativos que aumentam a "força"; a sucessão, segundo a legislação marfinense, é patrilinear; as ordálias (às quais outrora o acusado poderia ser submetido) são proibidas, mas a acusação pode se tornar confissão, ao transferir o caso a um "profeta" que, inspirado pelo deus dos Cristãos e, indiretamente, pelo presidente Houphouët-Boigny, confessa os "diabos". Em Bregbo, minha simples presença, mesmo sendo decididamente muda, não é inocente; ela traz "uma prova suplementar da existência dos diabos, do conhecimento do profeta" e da legitimidade da política de desenvolvimento do Estado

\footnotetext{
${ }^{34}$ Uma das "condições favoráveis do trabalho etnográfico" é, diz ele, armar sua barraca bem no centro da aldeia indígena, mas é "muito agradável" poder buscar refúgio entre os brancos quando estamos "saturados de indígenas" (1963 [1922], Introdução, IV).

35 “30 de março de 1918: Voltei; li Maud Diver, e não dei a mais mínima importância aos niggers" (1985 [1967], p. 238).
} 
marfinense ${ }^{36}$. Se meu objetivo fosse apenas catalogar os costumes aladianos, minha descrição do que eles fazem seria muito parcial.

A proposta, feita por Georges Balandier nos anos $1950^{37}$, de que 0 que observo, na verdade, não é um vilarejo kongo ou uma tribo fang, mas uma situação colonial, ainda não deixou de exercer, de certa maneira, seus efeitos subversivos na disciplina. A relação dos etnólogos com a dominação colonial ou pós-colonial não é de servidão, mas de denegação. Tudo acontece como se eles não a vissem e sua cumplicidade "objetiva" resume-se, geralmente, em fingir que ela poderia não ser visível, esse processo de apagamento erudito não excluindo, além disso, que seus artesãos, por outro lado, se vejam como os denunciadores eloquentes dos malefícios do colonialismo. No espaço de autenticidade restrito assim constituído por uma operação de subtração, coexistem culturas indígenas. É "indígena" tudo que sobra, uma vez fora do escopo, o "exógeno", i.e., o conjunto das condições históricas efetivas e das relações sociais atuais em que se deu a observação de "campo". É esse "resto" que é transformado em totalidade orgânica na e pela monografia que lhe é dedicada. A "cultura indígena" tem um modo de existência ideal e acrônica (o "presente etnográfico" é um aoristo). É precisamente esse status de objeto ao mesmo tempo sublime e efêmero que contribui para justificar as ações militantes empreendidas para a proteger contra a destruição, mesmo que isso signifique colocá-la em uma "reserva", em algum museu vivo.

Não posso dizer: apenas o contexto da minha observação é colonial (ou pós-colonial), não o que observo. Em 1963, durante uma cerimônia banal de enterro na costa oeste de Madagascar, a europeização mimetizada e ostensiva que marca alguns momentos da cerimônia não é um efeito lamentável da aculturação, mas uma forma de criar uma identidade partilhada, por referência à condição comum de servidão ao poder estrangeiro, em que o observador é, apesar de si, o representante ${ }^{38}$. Não posso fazer como se, em um contexto político que serve apenas de cenário da pesquisa, estudasse uma certa forma, dogon ou bété, de ser humano, de viver em sociedade ou de ver o mundo. Porque é justamente nessa situação que aqueles que observo "são" Bété ou Dogon, i. e. que eles se pensem e se querem como tais. É a sociedade colonizada que está dividida etnicamente ${ }^{39}$. Os processos de identificação étnica se dão sobre a base dessa sujeição uniforme, como em toda conjuntura em que as antigas unidades políticas foram apagadas, reduzidas a estados de vestígios, entre lembranças e simulações, condenadas à reprodução

\footnotetext{
${ }^{36}$ M. Augé, 1975, p. XV. "Dessa construção [...], o observador se transforma rapidamente (no melhor dos casos, sem que perceba) em um dos arquitetos".

${ }^{37}$ G. Balandier, 1963 [1955]. Como observa M. Augé, é significativo que Balandier tenha preferido a sociologia: a etnologia não consegue ser "atual". No entanto, Balandier observa (particularmente na segunda edição de sua obra, 1963, p. 36) que a antropologia social anglo-saxã descobre paralelamente a "situação colonial": ver os trabalhos de Peter Worsley para a Melanésia, os de Gluckman e seus estudantes (a "Escola de Manchester") para a África. Desde 1940, Gluckman (nascido em Joanesburgo e formado na universidade de Witwatersrand) mostrava como "sociedade negra" e "sociedade branca" deveriam ser consideradas como constituindo uma mesma "situação" (M. Gluckman, 1940).

${ }^{38}$ Ver G. Althabe, 1969, p. 135.

${ }^{39}$ Ver G. Balandier (1963 [1955], p. 20): “A sociedade colonizada está dividida etnicamente”.
} 
comemorativa, à existência unicamente "cultural". A etnicidade é uma figura da alienação: dentro do território do Estado (ou do Império), cada um enfatiza-se radicalmente como o outro do outro. Ser Bété é uma forma não baoulé de ser da Costa do Marfim $^{40}$, como ser Dogon é uma forma não fulani de ser Malês. Obviamente, é verossímil que os habitantes das falésias de Bandiagara consultassem suas raposas-oráculos bem antes da conquista colonial e das primeiras pesquisas do Tenente Desplagnes, mas isso ainda não se dava sob um signo étnico. Antes de virem a ser Dogons, os Dogons não sabiam que eles tinham costumes dogons.

Durante esse trabalho complexo de estabelecer e promover essas identidades étnicas, o etnógrafo profissional traz sua contribuição, mas em uma estreita imbricação, tanto a montante quanto a jusante, com diversas práticas de etnografia "não acadêmicas" (administração colonial, missionários, eruditos locais, letrados urbanizados...) ou "populares" (invenção ou renovação dos costumes "tribais"...). Etnografar é inscrever em nome de um suposto sujeito coletivo uma série de "traços" característicos, da mesma forma como estabelecemos uma ficha sinalética de um indivíduo ao anotar seus "sinais particulares". É muito difícil que eu não participe de alguma forma dessa operação, mesmo que pela leitura local que será feita daquilo que escrevo. Torno público um saber que cada um se apropria à sua maneira. Sou, portanto, como aqueles que, por bem ou por mal, disponibilizam no "mercado" nacional referências identitárias consumíveis. Assim, eu não sou o observador de uma "cultura", mas um observador de seus produtores. Marcel Griaule, Germaine Diertelen ou Jean Rouch são os coautores de cultura dogon, assim como Ambara ou Ogotemmêli, o que surpreenderá apenas aqueles que recusam reconhecer que uma cultura existe, $i$. e. "se revela", a não ser pelo "olhar de uma outra cultura", em uma "exotopia" essenciall ${ }^{41}$. Não que a cultura dogon não seja sua invenção conjunta, mas porque o modo de ser de toda cultura é o da obra, da opus operatum. O mesmo acontece quando rastreio ou faço o inventário dos usos e costumes de um "país" ou de um vilarejo de alguma província francesa, ou que identifico as formas específicas de ser de um bairro de uma grande cidade. Vivemos em um mundo de etnografia generalizada onde se multiplicam, com o apoio dos poderes locais ou do Estado, preocupados em conservar o "patrimônio etnológico", os compositores-intérpretes de uma miríade de "microculturas". Depois do "espírito do povo", o espírito provinciano.

Mas na medida em que analiso uma situação, eu não "etnografo". Esses processos e procedimentos de identificação, e, portanto, eventualmente a própria atividade etnográfica, profissionais ou não, fazem parte das ações que descrevo. Em vez de interpretar os comportamentos como manifestações fenomenais de um sujeito metassocial, tomo essa mesma hermenêutica como uma atividade eminentemente social e eventualmente eficaz em uma conjuntura dada,

\footnotetext{
${ }^{40}$ Ver J.-P. Dozon e J.-P. Chauveau, 1987, p. 221-296.

${ }^{41}$ Ver M. Bakthin, 1984, p. 346-348. Ver também J. A. Boone: “Uma 'cultura' pode se materializar unicamente em contradistinção a outra cultura. Esta afirmação [...] meramente reconhece que antes de qualquer cultura poder ser experienciada como uma cultura, o deslocamento a partir dela deve ser possível" (1982, p. IX)
} 
às vezes terrivelmente destrutiva. Cada "cultura" ou "microcultura" é uma "jogada" tática bem-sucedida, seja para fazer com que seja reconhecido ou legitimado seu direito a ser outro que os outros ${ }^{42}$, seja para reduzir os outros a sua inelutável incapacidade de ser como si mesmo. Como tal, não instituo uma identidade, descrevo as modalidades e os procedimentos de sua instituição, por exemplo, a retórica e a mimesis da "etnicidade", como descrevo a arte e a maneira de tirar proveito ou poder, de se colocar bem no centro do campo concorrente das identidades disponíveis ${ }^{43}$, de reivindicar seu pertencimento às mais valorizadas todas práticas que têm justamente o efeito de as reproduzir. Quando somos o eterno "Rmiste" ${ }^{44}$ cuja mulher "trabalha como doméstica", no $2^{\circ}$ andar da escadaria B, como continuar, ao menos, a pertencer à categoria dos "franceses nativos" puros, senão devolvendo a família Mohammed, do $4^{\circ}$ andar, à sua fundamental e inalterável arabidade, através de uma acusação incessante que transforma $o$ mais insignificante dos comportamentos em um símbolo étnico ("ah, só podia ser coisa de árabe $\left.{ }^{45} ! "\right)^{46} ?$

Observo sempre apenas situações. Uma situação é uma configuração singular por definição temporária, o momento atual de uma história em curso, em que é possível elaborar um estado. Em relação a isso, estou reduzido ao lote comum das ciências sociais, tal como elas foram definidas por Jean-Claude Passeron ${ }^{47}$. No entanto, ainda que 0 conhecimento que adquiro progressivamente sobre aquilo que eles fazem seja histórico, geschihtlich ("historial"), não implica que ele seja necessariamente historiográfico.

Não é necessário dizer que, nos múltiplos conhecimentos que coleto "em campo", alguns dizem respeito ao passado. Faço com que ele me seja contado ou o estabeleço recorrendo a documentos de arquivos. Cada nova ação é o resultado de uma série de ações anteriores. Além desse cadáver que interrogamos, existem muitos outros "no armário". É preciso, portanto, que possa reconstituir, da melhor forma possível, a coisa toda, a série de sucessões contestadas à frente da linhagem que leva à acusação hoje, os episódios sucessivos do conflito das facções que levam à crise atual. Mas, embora ela possa eventualmente levar a um

\footnotetext{
$42 \mathrm{O}$ famoso "direito à diferença" é um direito à alteridade. Uma diferença é um fato dado, ela não pode ser decretada. A alteridade pode ser temida, invejada, odiada, amada..., uma diferença pode apenas ser estabelecida e descrita.

${ }^{43}$ Ver as análises de J.-L. Amselle em 1990, capítulo III.

${ }^{44}$ Um "rmiste" ou "erremista" é uma pessoa que recebe o RMI, ou seja, a renda mínima de integração. Esse subsídio foi pago entre 1988 e 2009, na França, pelos fundos do abono de família a pessoas com recursos abaixo de um determinado limite [ndt].

${ }^{45}$ No original, “ah, c'est bien des bougnoules!", a expressão "bougnoule" é uma forma pejorativa de designar a pessoa originária do Norte da África, utilizada desde os tempos do colonialismo. Por extensão, é uma forma racista de tratar os magrebinos e árabes, e os indivíduos de pele negra ou mestiça [ndt].

${ }^{46}$ Ver G. Althabe, 1993, p. 217-227.

47 1991, p. 358: as ciências sociais são "necessariamente históricas"; elas “podem estar baseadas apenas em observações de "configurações singulares" jamais repetidas em sua totalidade [...]".
} 
exercício micro-histórico que se torna ele mesmo seu próprio fim, essa perspectiva historizante é aqui instrumental. O que pretendo estabelecer não é o que realmente aconteceu, mas, para um caso dado, a "sintaxe" ou a "lógica" das ações plausíveis.

Do conhecimento antropológico, "o último objetivo, diz LéviStrauss, não é saber o que são, cada um por sua própria conta, as sociedades que nós estudamos, mas de descobrir em que diferem umas das outras ${ }^{48}$. Esse interesse pela variedade e pela variação dos comportamentos humanos sempre é provisoriamente ideográfico diferentemente do conhecimento histórico ou etnográfico, ele não acampa no particular ${ }^{49}$ - e não se pensa como explicativo, mas descritivo.

No entanto, os "desvios diferenciais" de que trata Lévi-Strauss separam e ligam "sistemas de signos". Para que um signo exista, basta que ele seja atestado por uma etnografia qualquer. Deixando de ser a marca de um sujeito coletivo (o espírito de um povo), cada signo transforma-se na assinatura de seu último autor, o "espírito humano". A antropologia continua sendo, assim, o que ela é desde Frazer: uma ciência comparada dos costumes ou do conjunto dos costumes, as culturas, portanto, das obras, e não dos atos. Censurar Lévi-Strauss de não ter se preocupado em saber se tal regra de casamento é efetivamente seguida ou mesmo de ter acreditado que como ela existe, a seguimos, é inútil: se ela foi formulada por alguém em algum lugar, mesmo que fosse um legislador louco, ele é um dos produtos do espírito humano. Do mesmo modo, basta que os indígenas de Ambrym desenhem sobre o chão, para explicar a Deacon, o diagrama complicado de seu sistema matrimonial de seis classes $^{50}$, ainda que saber desenhar um diagrama e se casar sejam comportamentos diferentes e sem uma relação necessária, como esboçar um mapa de uma floresta e passear por ela. Não é problemático que algum mito bororo não tenha outro tipo de existência a não ser o texto definitivamente extraído de sua situação inicial de enunciação por um missionário cuidadoso, se suponho que os Bororo, quando contam seus mitos, não estão fazendo outra coisa a não ser trazer seu eco à coleção de mitos ameríndios. Com todos seus signos, fragmentos de uma das culturas entre as quais a humanidade se acha dividida arbitrariamente, seja o canibalismo dos Tupi ou $A$ busca do tempo perdido, podemos escrever, através da análise estrutural ou do comentário hermenêutico, uma nova obra.

Ao não ser possível saber o suficiente para descrevê-lo como uma ação ou porque me é indiferente considerá-lo sob este ângulo, da mesma forma como me é inútil, para apreciar um quadro de Klee, saber como procedeu para fabricá-lo ou a qual preço ele foi vendido, todo comportamento humano pode ser tratado como um signo. Mas também

\footnotetext{
481973 [1962], p. 81.

49 A expressão é de Lévi-Strauss. Como o historiador, “o etnógrafo se ancora no particular” (ibid., p. 15).

${ }^{50}$ Ver C. Lévi-Strauss, 1967 [1947], p. 146-147. ("Os indígenas (ou pelo menos os mais inteligentes) concebem seu sistema como uma mecânica bem organizada que eles podem representar através de diagramas [...]. A partir desses diagramas, eles tratam as questões de parentesco de uma forma totalmente comparável com aquelas que podemos esperar de uma boa síntese científica exposta em uma sala de aula", escreve Deacon).
} 
posso, inversamente, abordar qualquer signo como o vestígio de uma operação, ou de um conjunto complexo de operações, cujas regras podem ser conhecidas ou descritas. Neste caso, passar de um mundo a outro, do estranho ao familiar e vice-versa, faz parte de uma antropologia não mais semiológica, mas pragmática.

Posso contar um acontecimento (saber aquilo que realmente aconteceu) e tentar explicá-lo. Mas dois acontecimentos são, estritamente falando, rigorosamente incomparáveis. De uma singularidade, posso apenas imaginar que ela se repete. No entanto, o sistema virtual das regras que as ações, em Grand-Jacques ou em Nantes, respeitam, é uma ordem transformável (ou deformável). Devo poder mostrar que, mutatis mutandis, ele é uma variante de um outro. Retomando uma analogia cujo único mérito é ser a menos ruim, qualquer que seja o jogo que eles jogam, devo poder estabelecer que ele é diferente, e diferente unicamente, de qualquer outro, mesmo daqueles que jogo normalmente. É essa hipótese que testo em cada uma dessas experiências em que, não sabendo bem o que eles fazem, tenho que tentar aprender.

É por isso que, na medida em que esse interesse antropológico toma a dianteira sobre o gosto muitas vezes desenfreado pelo exercício monográfico, escrevo na modalidade do possível, e não na do real, modalidade dominante do discurso histórico. Escrevo o que é, em um contexto dado, a escolha das ações plausíveis, não explico fatos. Tenho, portanto, com a história, sensivelmente, a mesma relação que Maquiavel mantinha com Tito Lívio, ao mesmo tempo atenta e livre, para não dizer despreocupada. Pouco importa Roma, se o interesse de Roma é apenas apresentar, através dos séculos, suficientes diferenças pertinentes com Florença para que possamos construir o campo da ação política, i. e., abordar as contingências, aquilo que verdadeiramente aconteceu, como variações efetuadas de um mesmo universo de possíveis. 
Espaço Ameríndio

\section{Referências bibliográficas}

ALTHABE, Gérard. Construction de l'étranger dans les échanges quotidiens, Civilisations, "En quête d'identité", v. XLII, Institut de sociologie de l'Université Libre de Bruxelles, Bruxelles, p. 217-227, 1993.

ALTHABE, Gérard. Ethnologie du contemporain et enquête de terrain, Terrain, "L'incroyable et ses preuves", n. 14, 1990

ALTHABE, Gérard. Oppression et libération dans l'imaginaire. Paris: François Maspero, 1969.

ALTHABE, Gérard; MARCADET, Christian; DE LA PRADELLE, Michèle; SÉLIM, Monique. Urbanisation et enjeux quotidiens. Terrains ethnologiques dans la France actuelle. Paris: Anthropos, 1985.

AMSELLE, Jean-Loup. Logiques métisses. Paris: Payot, 1990.

AUGÉ, Marc. Le rivage Alladian. Organisation et évolution des villages alladian. Paris: ORSTOM, 1969.

AUGÉ, Marc. Théorie des pouvoirs et idéologie. Étude de cas en Côte d'Ivoire. Paris: Herman, 1975.

BAKTHIN, Mikhail. Esthétique de la création verbale. Paris: Gallimard, 1984.

BALANDIER, Georges. [1955]. Sociologie actuelle de l'Afrique noire. Dynamique des changements sociaux en Afrique centrale. Paris: PUF, 1963.

BAZIN, Jean. Des clous dans la Joconde. L'anthropologie autrement. Toulouse: Anacharsis, 2008.

BAZIN, Jean; BENSA, Alban. Avant-propos In: Goody, Jack. La raison graphique. La domestication de la pensée sauvage. Paris: Minuit, 1979, p. 7-29.

BENSA, Alban; RIVIERRE, Jean-Claude. De l'histoire des mythes. Narrations et polémiques autour du rocher Até (Nouvelle-Calédonie), L'Homme, "Les métamorphoses du mythe”, n. 106-107, XXVIII (2-3), 263-295, 1988.

BOON, James A. Other tribes, Other Scribes. Cambridge; Cambridge University Press, 1982.

DESCOMBES, Vincent. Grammaire d'objets en tous genres. Paris: Minuit, 1983.

DESCOMBES, Vincent. Philosophie par gros temps. Paris: Minuit, 1989.

DOZON, Jean-Pierre; CHAUVEAU, Jean-Pierre. Au coeur des ethnies ivoiriennes...l'État, In: TERRAY, Emmanuel. L'État contemporain en Afrique. Paris: L'Harmattan, p. 221-296, 1987. 
Espaço Ameríndio

GLUCKMAN, Max. Analysis of a Social Situation in Modern Zululand, Bantu Studies, v. XIV, n. 1 e n. 2, 1940.

GRIAULE, Marcel; DIETERLEN, Germaine. Le renard pâle. Paris: Travaux et mémoires de l'Institut d'Ethnologie, 1965.

LA PRADELLE, Michèle de. Les vendredis de Carpentras. Faire son marché en Provence ou ailleurs. Paris: Fayard, 1996.

LACAN, Jacques. Le séminaire, Livre IV, La relation d'objet, 1956-1957. Paris: Le Seuil, 1994.

LEACH, Edmund. Culture and communication. Cambridge: Cambridge University Press, 1976.

LEIRIS, Michel. [1934]. L’Afrique fantôme. Paris: Gallimard, 1981.

LÉVI-STRAUSS, Claude. [1962]. Anthropologie structurale II. Paris: Plon, 1973.

LÉVI-STRAUSS, Claude. [1962]. Antropologia estrutural II. Rio de Janeiro: Tempo Brasileiro, 1993.

LÉVI-STRAUSS, Claude. [1947]. Les structures élémentaires de la parenté. Paris: La Haye, Mouton, 1967.

MALINOWSKI, Bronislaw. [1967]. Journal d'ethnographe. Paris: Le Seuil, 1985.

MALINOWSKI, Bronislaw. [1922]. Les Argonautes du Pacifique occidental. Paris: Gallimard, 1963.

NIETZSCHE, Friedrich. Fragments posthumes. Hiver 1872-1873. In: Oeuvres philosophiques complètes, v. II, t. 1. Paris: Gallimard, 1990.

PASSERON, Jean-Claude. Anthropologie et sociologie, Raison présente, n. 108, p. 134, 1993.

PASSERON, Jean-Claude. Le raisonnement sociologique. L'espace non-poppérien du raisonnement naturel. Paris: Nathan, 1991.

REVEL, Jacques; WACHTEL, Nathan. Une École pour les sciences sociales. De la VIe section à l'École des hautes études en sciences sociales. Paris: Éditions du Cerf/Éditions de l'EHESS, 1996.

WITTGENSTEIN, Ludwig. [1969]. Grammaire philosophique. Paris: Gallimard, 1980. 
Recebido em: 02/08/2020 * Aprovado em: 16/09/2020 * Publicado em: 16/12/2020 